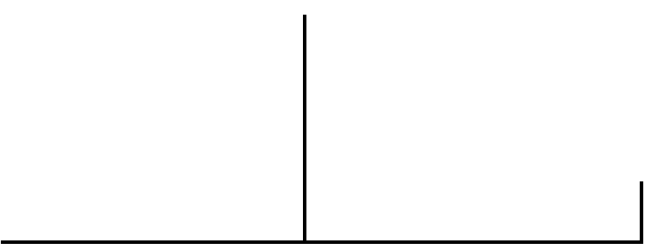

Rev. Latinoam. Psicopat. Fund., IX, 4, 583-597

\title{
Dissociação, experiência e narrativa - um estudo de caso
}

\author{
Marcelo Kimati Dias \\ José Luiz dos Santos
}

Dissociação da consciência é um fenômeno que ocorre tanto em situações culturalmente sancionadas, como rituais religiosos, quanto dentro de contextos médicos. As classificações diagnósticas procuram diferenciar estes episódios em dois fenômenos distintos. Ainda que haja esta tentativa, indivíduos que apresentam quadros dissociativos freqüentemente procuram diferentes possibilidades interpretativas desse fenômeno. O presente estudo procura, por meio de uma etnografia centrada na pessoa, descrever o itinerário de diferentes saberes percorrido por uma paciente com episódios dissociativos. Identificamos ainda que a construção da narrativa da experiência dissociativa apresenta especificidades relacionadas ao fenômeno psicopatológico da dissociação.

Palavras-chave: Dissociação, etnografia centrada na pessoa, narrativa, psiquiatria cultural 


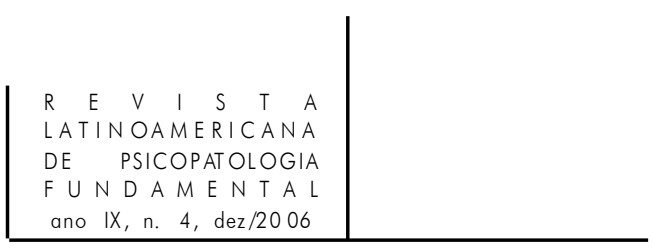

\section{Introdução}

O conceito de dissociação remonta, dentro da psiquiatria, ao final do século XIX, quando Pierre Janet desenvolveu a expressão "dissociação mental” a partir de observações clínicas. Janet descreveu um fenômeno no qual eventos de vida traumáticos levavam pacientes a ter lembranças inacessíveis à consciência - lembranças dissociadas do restante da memória. Esses pacientes apresentavam, em função do fenômeno, alterações de identidade e consciência. Tais episódios poderiam ser revertidos, segundo observações clínicas de Janet, mediante hipnose, trazendo à consciência lembranças anteriormente inacessíveis, com melhora dos sintomas.

Hoje, parte dos psiquiatras identifica o termo dissociação com um grupo heterogêneo de fenômenos. Estes envolveriam tanto uma experiência vivida por pacientes que apresentassem alterações da integração de diferentes funções psíquicas, quanto a expressão comportamental desta falha (Kirmayer, 1994). A partir desta diversidade de fenômenos, as experiências dissociativas podem ser tanto vivências emocionais como cognitivas ou processos sociais.

A categorização destes fenômenos dentro da nosologia psiquiátrica atual foi construída a partir de 1952 quando passaram a vigorar os manuais diagnósticos. Estes constituíram inicialmente uma iniciativa da psiquiatria norte-americana de unificar diferentes sistemas de classificação. A primeira edição do Manual Diagnóstico e Estatístico dos Transtornos Mentais (DSM-I) da Associação Psiquiátrica Norte-americana (APA) separa os aspectos ligados à histeria em duas diferentes categorias: os fenômenos dissociativos e conversivos. Ao mesmo tempo em que houve esta segmentação, a própria histeria deixou de ser considerada um diagnóstico. Para Neliah (2000), o abandono do conceito pela psiquiatria deve-se ao seu uso indiscriminado no passado. No mais recente manual diagnóstico da APA, o DSM-IV aparecem como categorias relacionadas a estes aspectos histéricos o transtorno de personalidade histriônico, os transtornos conversivos e os transtornos dissociativos.

Atualmente, a literatura médica sugere que as categorias da CID-10 têm se mostrado inadequadas para realizar diagnósticos ligados a fenômenos dissociativos em populações não ocidentais (Haugen e Castillo, 1999; Sar, Tutkun, Alyanak, Bakim, Baral, 2000). Existe ainda a hipótese de que populações que vivem em culturas nas quais fenômenos dissociativos são 


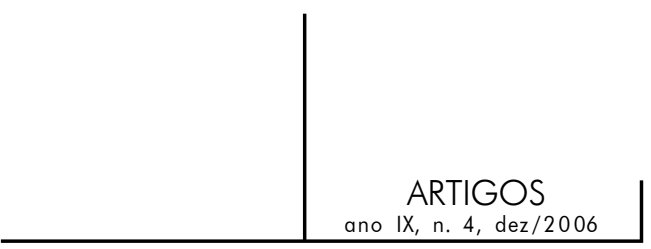

comuns em práticas religiosas sejam mais propensas a apresentar tais transtornos como idioma de estresse (Kirmeyer, 1994).

As categorias ligadas aos fenômenos dissociativos incluem tanto situações culturalmente limitadas quanto situações de procura de ajuda médica. A diferenciação do caráter que o fenômeno adquire apóia-se no status médico que o evento adquire ou não. Receber ou não o diagnóstico implica exposição a procedimentos previstos pela psiquiatria. De forma análoga, Kleinman (1988) discute como ouvir a voz da esposa morta durante o luto pode ser um fenômeno normal entre índios americanos, ainda que categoricamente possa ser considerada uma alteração senso-perceptiva por um psiquiatra treinado. Para o autor, a questão recai na validade do diagnóstico psiquiátrico, ou seja, o quanto observações psiquiátricas podem encontrar respaldo na realidade. No caso da dissociação, a pergunta talvez seja o quanto é verificável o pressuposto de que um fenômeno de possessão pode ser considerado um transtorno tratável.

Existe hoje uma ampla discussão sobre a validade diagnóstica dos transtornos dissociativos, particularmente do transtorno dissociativo de identidade. Pope (1999) realizou um estudo com psiquiatras norte-americanos, enviando questionários a 367 deles perguntando sobre a validade dos diagnósticos de Transtorno de Amnésia Dissociativa e Dissociativo de Identidade. Apenas um terço dos psiquiatras consultados opinou que estas categorias deveriam ser aceitas sem restrições nos manuais diagnósticos, e apenas um quarto acha que existiam evidências que sustentassem a validade das categorias. Por outro lado, uma revisão da literatura médica sobre o tema, realizada por Gleaves, May e Cardeña (2001) apontou para a viabilidade de inclusão do diagnóstico de Transtorno Dissociativo de Identidade nos manuais diagnósticos, ainda que com algumas restrições aos critérios de inclusão.

Kirmayer (1994) procura sistematizar a ocorrência destes fenômenos dentro de três situações distintas: 1) em contextos culturalmente delimitados, como um comportamento sancionado; 2) como idioma de estresse; ou 3) como um fenômeno psíquico que é comum na infância (rêverie), mas que diminui ao longo da vida. Ainda que haja um esforço no sentido de estabelecer critérios que delimitem a dissociação vista como produto de práticas culturais daquela passível de intervenção médica, não há evidências que pacientes atendidos por transtornos dissociativos não tenham experiências religiosas que incluam fenômenos de dissociação. Ao contrário, a procura por diferentes leituras do mesmo fenômeno ocorre no país seguidamente ou, com freqüência, de forma simultânea.

Kleimnan (1980) descreve o sistema de saúde como um sistema socialmente organizado de resposta à doença. Em Patients and Healers in the Context of Culture, o autor propõe que os personagens deste sistema, como curadores e pacientes, têm sua relação mediada por configurações e significados culturais 


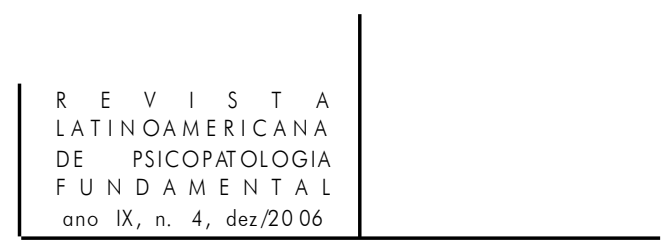

específicos. Práticas de cura e sistemas de representação oferecidos por religiões afro-brasileiras, pentecostais e pela psiquiatria fariam parte de um mesmo sistema, ainda que em muitas situações representem antagonismos.

O presente estudo procura discutir as relações entre a trajetória de pacientes que apresentam dissociação por diferentes formas interpretativas do fenômeno e suas particularidades psicopatológicas. Procuramos discutir ainda como a narrativa é construída a partir destas experiências dissociativas e quais os desdobramentos da narrativa dentro das relações sociais.

\section{Método}

A descrição a seguir trata de um estudo de caso de uma paciente que foi acompanhada prospectivamente por seis meses após haver sido captada num serviço psiquiátrico hospitalar no segundo semestre de 2000. O estudo de caso foi o método escolhido por possibilitar o exame cuidadoso da trajetória de uma paciente, dentro e fora do âmbito médico. Ainda que estudos em larga escala possam demonstrar associações entre o itinerário de vários pacientes e escores de sintomas dissociativos, um estudo retrospectivo não nos permitiria explorar a experiência frente a dissociação, um dos eixos de nossa discussão. Por outro lado, um estudo meramente psicopatológico não nos permitiria observar a articulação entre o fenômeno psíquico e a cultura.

A etnografia centrada na pessoa (Hollan, 1997), o método que utilizamos a seguir, diferencia-se de uma etnografia tradicional por ter como referência a descrição e análise do comportamento, da experiência subjetiva e os processos psicológicos subjacentes. Em contraste com a etnografia clássica, não prioriza a descrição da organização e da estrutura social de uma comunidade, mas como um personagem, escolhido, experimenta essa estrutura.

O caso descrito neste estudo é o de uma paciente que, após breve internação, foi entrevistada em sua casa junto aos seus familiares. Após dois meses de seguimento e entrevistas, foi novamente hospitalizada.

\section{Aparecida}

Aparecida tem hoje 47 anos, é casada, freqüentou a escola por apenas quatro anos. Aparecida nasceu na zona rural do interior de São Paulo e seus pais eram católicos. Ao contrário, toda a família de seu marido era espírita, ainda que ele 


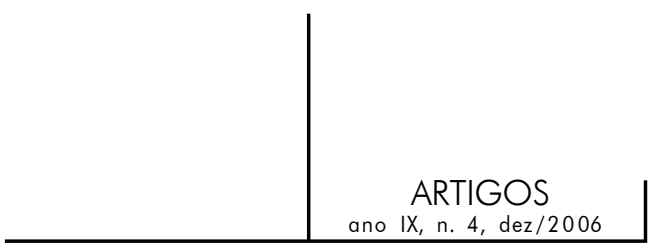

próprio não fosse praticante. Seu contato com a psiquiatria data de vários anos, alguns após o início do casamento que já dura 25.

Contou que alguns meses após casar-se passou a apresentar brigas com o marido. Nas horas subseqüentes a essas brigas andava a esmo durante muito tempo pela cidade e pouco se lembrava do ocorrido. Depois de três meses do início do problema, suas caminhadas foram vistas pela sua sogra como um "transe", possivelmente relacionado a algum tipo de entidade. Recomendou então que Aparecida procurasse um centro espírita do qual fazia parte na época. Aparecida conta que achou aquilo um absurdo na ocasião, porque associava espiritismo às religiões afro-brasileiras. Após um período de discussões, concordou em procurar uma igreja pentecostal que, segundo sua sogra, a ajudaria mais do que a igreja católica. Procurou então a Congregação Cristã do Brasil.

Durante quase seis meses Aparecida foi várias vezes por semana aos cultos da Congregação. A igreja era pequena e a freqüência com que os fiéis iam ao culto era muito grande. Fez várias amigas - conta que na ocasião, as "irmãs" consideravam seu caso grave, mas que poderia melhorar aceitando Jesus. Em alguns cultos que considerava mais agitados, quando as orações eram muito intensas, caía no chão e sacudia seus membros, tronco, falando com voz gutural palavras ininteligíveis. Na primeira ocasião, foi levada a uma sala anexa à igreja. Oraram até que Aparecida melhorasse e então ligaram para que seu marido fosse buscá-la.

A partir do segundo episódio, suas “irmãs” passaram a olhá-la de uma forma diferente e demonstrando temê-la. Algumas se afastaram. Apesar dessas quedas serem ruins para suas relações dentro da igreja, ela continuava desejando que elas ocorressem. Após esses episódios mais intensos ela se sentia tranqüila e aliviada. Conta que passou a ter menos episódios de caminhar a esmo e sua relação com seu marido melhorou na ocasião. Ele conta hoje que ela passou a insistir para que ele freqüentasse a mesma igreja.

Após dois meses da primeira crise dentro da igreja suas relações com os fiéis estavam deterioradas. Resolveu abandonar a igreja e passou a fazer uma "peregrinação" por outras religiões cristãs. Conta que "ia onde mandavam ir”. Voltou a ter crises em casa e depois delas, caminhava sem rumo. Conta que "dava branco" depois das discussões com o marido. Foi levada a um neurologista pela sua sogra que pediu vários exames, entre eles três eletroencefalogramas que considerou normais. Encaminhou Aparecida a um psiquiatra. Esses episódios passaram a piorar, levando seu marido a trancá-la em casa quando saía para trabalhar.

A partir do momento em que deixou de ir à Congregação Cristã, Aparecida conta que já não possuía controle nenhum sobre o que lhe acontecia. Sua família considerava um fracasso a falta de melhora na igreja e tomava as decisões de seu dia a dia. Ela já não decidia o que comeria nas refeições ou o que faria ao longo 


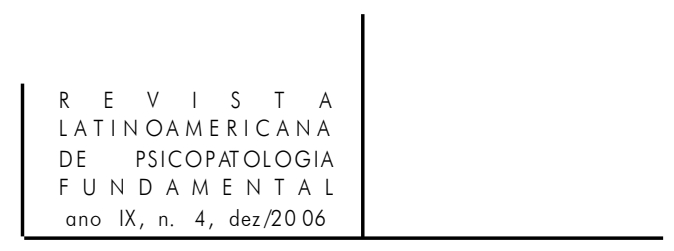

do dia. O fato de haver sido levada ao médico lhe conferiu status de mulher "doente da cabeça”. Foi então internada em um hospital psiquiátrico durante quase dois meses. Teve alta hospitalar (não apresentou crises por vários anos). Freqüentava esporadicamente a missa católica com concordância do marido. Criava sozinha os filhos que cresciam e não trabalhava. Por muitos anos prescindiu de ajuda médica. Voltou pouco a pouco a ter autonomia, a decidir sobre sua vida, conseguiu emprego, cuidava sozinha de seus filhos.

Para Aparecida os problemas apresentados foram ao longo dos anos vistos de forma diferente. "Eu mesma vejo tudo diferente a cada dia. Quando lembro daquela época, tenho saudade das irmãs da igreja que até hoje me ligam algumas vezes. Se nada tivesse acontecido eu não teria conhecido elas. Mas se tivesse parado de ter os ataques nos cultos estaria lá até agora”. Aparecida acentua um aspecto importante de suas crises dissociativas naquele momento: a impossibilidade de controle. Estabelece um paralelo entre a perda de poder que a levava aos episódios dissociativos e o seu trajeto em busca de ajuda. Acha que o médico que a acompanhara não soube entender o que estava acontecendo. "Os médicos de hoje perguntam muito mais - na época eu não era doente. Eu achava que estava doente, mas não estava. Não perguntaram como eu me sentia. Eu estava sozinha, minha família morava na roça. Depois de casar vi minha mãe, que já morreu, só duas vezes antes de internar.” Conta que sequer se lembra do nome dos médicos que a acompanharam nesse primeiro período.

Após haver vivido bem por quase vinte anos, Aparecida voltou a apresentar episódios dissociativos. No início do ano em que foram realizadas as entrevistas, seu filho João foi preso portando maconha e crack. Como já havia sido detido anteriormente, foi levado à cadeia antes do julgamento. A crise precipitou-se quando seu marido achou justa a prisão de João com quem se dava muito mal. Aparecida passou a visitar seu filho sozinha na cadeia, e após esses encontros ficava andando a esmo pela cidade sem perceber que o tempo passava.

Passou a discutir novamente com seu marido com muita freqüência, e após algumas dessas brigas começou a fazer uso de álcool. Ficava embriagada e andava pela cidade, o que fez com que fosse chamada de "vadia e desocupada" pela família de seu marido. Em algumas ocasiões perdeu o controle e agrediu sua sogra e marido que passaram a identificá-la ao filho preso. "Ele [o marido] dizia que eu e João éramos feitos da mesma coisa”. Havia parado de dormir e sentiase muito irritada e por isso aceitou fazer acompanhamento médico num centro de saúde, levada pela sogra. Conta que deu-se muito bem com a psiquiatra que não permitia que sua sogra entrasse no consultório.

Aparecida procurou então a Igreja Universal do Reino de Deus a partir de sua principal via de entrada: o culto da libertação que ocorre às sextas-feiras. Esse culto é especialmente voltado para o exorcismo e para a cura. Numa preleção do 


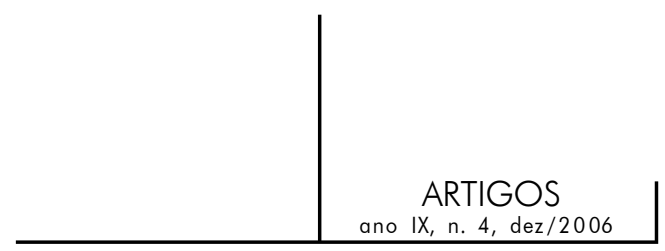

pastor todas as queixas que levam os fiéis a igrejas são atribuídas à presença do demônio na vida deles. É freqüente que o pastor explique problemas médicos "inexplicáveis" como dores sem diagnóstico, homossexualismo e desvios de comportamento como obra do demônio.

Aparecida procurou a Universal durante algumas semanas consecutivas. "Caiu” em todas as vezes que foi, mas foi rapidamente atendida por obreiros, a quem cabem os exorcismos que consideram simples. Numa dessas quedas machucou-se e seu marido passou a se opor às suas idas à Universal. Aparecida foi novamente internada num hospital psiquiátrico, contra sua vontade, por 15 dias. Saindo, voltou à psiquiatra "para conversar”, já que não acreditava que pudesse melhorar com uso de medicações, pois compartilhava das concepções de etiologia da Igreja Universal. Passou a ir todas as semanas aos cultos, mas diferente do que ocorrera na Assembléia de Deus, sem estabelecer vínculos de amizade com outros fiéis. Conta que a igreja é muito grande e cada sexta-feira que vai os fiéis mudam. Passou a apresentar episódios dissociativos em sua casa, incorporava o demônio nos cultos e, segundo conta, era levada quase sempre à frente para ser exorcizada pelo próprio pastor, o que a colocava em posição de destaque no culto. Isso não resultava, porém, em amizades, status ou qualquer tipo de tratamento especial. Não foi mandada a outros cultos ou submetida a outros procedimentos.

Ainda que apresentasse episódios dissociativos muito freqüentemente ao longo dos meses que seguiram à última internação, estava mais calma em casa e seu marido não se queixava dela. Durante uma consulta médica apresentou um episódio dissociativo e sua psiquiatra a encaminhou para nova internação. O que sua psiquiatra denominava um transtorno psiquiátrico, Aparecida identificava como a mesma coisa que ela vinha fazendo na igreja.

\section{Discussão}

O caso descrito é bastante ilustrativo. Permite identificar os diversos saberes e práticas terapêuticas relacionados aos fenômenos dissociativos e sua inserção na trajetória de uma pessoa. Mais do que uma procura por cura, melhora ou alívio, verificamos um processo de reinserção da pessoa em seu mundo social. Os procedimentos ativados oferecem respostas que não são definitivas, mas permitem que Aparecida negocie em seu mundo social a partir de um mosaico de significados advindos daqueles saberes e práticas. Ela assim constrói uma narrativa, buscando restabelecer sua noção de eu. Esta unidade do eu aparece num âmbito psicológico e também num eu social, que orienta seus papéis e relações sociais. 


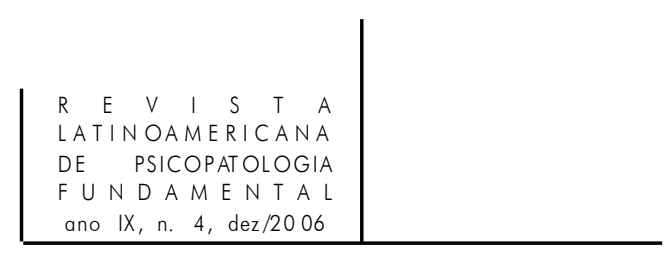

Os significados dos episódios dissociativos de Aparecida remetem a dois tipos de práticas específicas - religiosas (predominantemente pentecostais) e médicas (seguimentos psiquiátricos ambulatoriais e as hospitalizações). Estes significados atribuídos aos fenômenos dissociativos articulam-se e não se delimitam temporalmente. Ao contrário, aparecem como um jogo de idas e vindas que é retratado na narrativa de Aparecida.

A proposta do DSM-IV supõe que haja especificidade de fenômenos dissociativos que se encontrem sob controle ritual. Assim, a dissociação passível de tratamento corresponderia a um suposto idioma de estresse do qual um indivíduo faria uso. Existe uma dicotomia implícita de descontrole (do fenômeno em situações de caráter médico) e controle (em situações culturalmente sancionadas). No entanto, como vimos no caso descrito, indivíduos que apresentam episódios dissociativos em igrejas pentecostais podem freqüentar ambulatórios psiquiátricos de forma simultânea, fazendo uso e articulando diferentes representações sobre o fenômeno.

Redko (2000), num estudo realizado com pacientes num primeiro episódio psicótico, acompanhou e observou a construção e reelaboração de diferentes significados dos sintomas ao longo de vários meses, particularmente com referência ao papel de igrejas pentecostais nesse itinerário. Identificou o trânsito por diferentes modalidades religiosas como um fenômeno comum de significação da doença. Lewis (1977) mostra como alterações de consciência e identidade correspondem a alterações no status social dos participantes do culto. Isto corresponde a um ganho para indivíduos que são possuídos. Para o autor, "no estado de possessão o paciente é pessoa altamente privilegiada: permitem-se-lhe muitas liberdades com aqueles que em outras circunstâncias têm de ser tratados com respeito" (p. 33).

A literatura sugere que fenômenos dissociativos estão particularmente associados a uma multiplicidade de possíveis interpretações culturalmente estabelecidas. Somer e Saadon (2000) descrevem o Stambali como uma dança praticada por tunísios em Israel que induz o participante a um estado dissociativo com objetivo de exorcismo e cura. Beng-Yeong (2000) realizou estudo sobre episódios dissociativos em pacientes de três grupos étnicos (chineses, indianos e malaios) e verificou que ainda que houvesse uma proximidade fenomenológica dos eventos, as divindades incorporadas reportavam à cultura de origem dos pacientes. Hollan (1997), descreveu o contexto e os significados que podem adquirir episódios dissociativos existentes no ritual Ma'maro em Tana Toraja, Indonésia.

Esta parece ser uma particularidade da dissociação. Ainda que uma multiplicidade de interpretações possa ser vista em muitos outros fenômenos, episódios de dissociação ocorrem como componentes de diferentes rituais. Esta marca implica a possibilidade de pessoas que manifestem esse fenômeno transitarem por práticas referentes a esta multiplicidade interpretativa. 


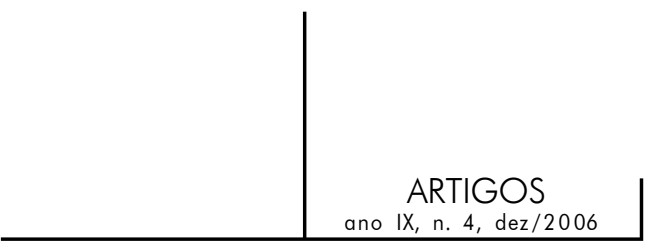

Dissociação, narrativa e experiência

Algumas características psicopatológicas dos fenômenos dissociativos podem estar implicados nesta possibilidade de trânsito por diferentes modelos explicativos. Kirmayer (1994) vê a dissociação como dois diferentes fenômenos: um comportamento e um mecanismo mental. Neste segundo caso, o processo envolve a perda de controle da integração de processos psíquicos.

Segundo um modelo da psicologia cognitiva, existem diversos estados de consciência que se alternam normalmente. Assim, a consciência do eu (self consciousness) estrutura-se segundo uma narrativa centrada no Eu e volta-se em direção à identificação que fazemos de nós, tanto segundo uma auto-imagem como na condição de atores sociais. Este estado relaciona-se ainda aos processos cognitivos que mantêm e reproduzem uma noção coerente do eu. A consciência do outro (other-consciousness) baseia-se numa narrativa voltada ao mundo externo, implicando o direcionamento da atenção para o outro (Kirmayer, 1994). Comportamentos automáticos como habilidades motoras, condicionamentos comportamentais, constituiriam um terceiro estado e um quarto, fenômenos de rêverie, comuns na infância, são relacionados a alterações de consciência que incluem imaginação e fantasia. A consciência atua no sentido de criar uma narrativa que articula a experiência subjetiva ao personagem que a pessoa desempenha socialmente.

A experiência é assim constituída num contínuo em que a consciência permite a criação de uma narrativa. Esta inclui tanto uma consciência do eu quanto a situação deste eu no mundo de relação. A experiência dissociativa constitui a perda desta continuidade. A existência de Gaps na narrativa gera, por sua vez, gaps na própria memória. Desta forma, a dissociação está envolvida numa quebra da experiência que inclui alterações de identidade, da relação com o outro e da memória.

O fato de a experiência dissociativa implicar em gaps da experiência do eu permite que a narrativa seja construída posteriormente à vivência do fenômeno e ao longo das relações com instituições e sistemas interpretativos, como no caso da psiquiatria. Isto torna esta experiência mais sujeita as diversas modalidades de representações sociais que o fenômeno mobiliza. A construção posterior da narrativa envolve diversas representações e saberes, faz parte da própria dissociação como mecanismo psíquico. A narrativa fragmentada é constantemente construída e reconstruída, reinterpretada e ressignificada ao longo do itinerário percorrido por aquele que dissocia. Nesse sentido, as categorias do DSM-IV discutidas inicialmente servem de elementos para um jogo social que envolve os pacientes e extrapola a psiquiatria. 


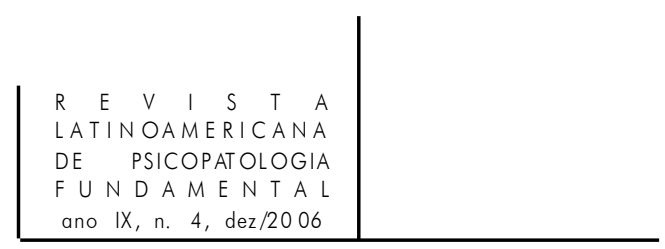

As condições da narrativa e papéis sociais

Observamos, portanto, como algumas particularidades da dissociação como fenômeno psicopatológico favorece a elaboração de uma narrativa. O caso relatado corresponde à própria narrativa de Aparecida, uma pessoa exposta a diversos fenômenos dissociativos. Esta história, que nos foi contada, trata da interpretação atual de Aparecida sobre estas vivências, a forma com que ela as expõe socialmente. Algumas características da narrativa podem ser discutidas no sentido de aprofundarmos esta discussão entre a relação dissociação e experiência.

Inicialmente, a narrativa tem um aspecto pragmático, tem sempre uma dimensão utilitária, como uma norma moral, uma sugestão prática, um provérbio. Benjamin (1987) descreve o narrador como alguém imbuído de um senso prático. Por outro lado, tanto a narrativa quanto a interpretação remetem a uma troca de experiências. Para Benjamin, a narrativa é definida como o intercâmbio de experiências. A narrativa de Aparecida mostra suas idas e vindas diante de diferentes saberes, mas mostra também sua inserção em diversos modelos de relação social. Na medida em que ela conta sua história, mostra a inserção das interpretações relacionadas aos seus episódios dissociativos em seu universo de relações. A narrativa serve ainda como uma reconstituição do eu. Segundo o que conta, a experiência de Aparecida fez dela consecutivamente uma vítima de uma possessão, uma mulher doente e a mãe de um preso. Narrar os episódios dissociativos e sua inserção em diferentes práticas é reconstituir-se. Narrar é um discurso inserido na cultura, que remete a práticas e papéis sociais. Para Scott (1999), a experiência não é uma vivência que incide sobre sujeitos, mas os sujeitos são reconstituídos pela experiência.

A medicina, neste sentido não apenas fornece uma interpretação como um papel social vinculado aos procedimentos aos quais Aparecida foi exposta. Ainda que tenha uma perspectiva muito específica a respeito dos fenômenos aos quais ela havia experimentado, sua médica foi tolerante com as outras práticas freqüentadas por Aparecida. De certo modo a própria psiquiatria terminou por legitimar as demais interpretações na medida em que as aceitou. Esta prática é comum e evitá-la inviabiliza muitas vezes a relação médico-paciente. Em Patients and Healers in the context of Culture, Kleinman descreve o encontro terapêutico envolto num sistema de trocas simbólicas nos quais os significados e as representações da doença são negociados. Um exemplo que encontramos desta legitimação e negociação de significados é o fato de Aparecida estabelecer um elo entre os dois períodos nos quais apresentou quadros dissociativos. Ainda que apresente diversas leituras sobre estas experiências, este vínculo temporal obedece a uma organização médica do fenômeno. 


\section{ARTIGOS}

Uma segunda condição para a existência de uma narrativa diz respeito ao consenso de que ela pode se valer. A narrativa se volta ao grupo e este deve sancioná-la. Aparecida, na medida em que narra sua trajetória e a interpreta, procura expor uma visão de si e de sua experiência na qual caiba uma noção de suas relações sociais. Para que a função pragmática da narrativa se concretize, os significados da experiência construídos por esta narração devem ser aceitos por seu grupo social de referência.

As diferentes práticas e representações que Aparecida mobiliza com seus episódios dissociativos visam atingir esse consenso. Diante da grande variabilidade e questões relacionadas à noção de pessoa, sobre sua extensão e limites, Mary Douglas (1992) estabelece em Thought Style Exemplified - The idea of the self, uma analogia entre as noções de self e de Deus. Para a autora, a saída encontrada para a definição de ambos é tornar o conceito inefável, inapreensível e apoiado exclusivamente numa idéia de consenso. O consenso precede ao significado.

Os significados (e representações) desta procura estão envolvidos com as práticas subjacentes a eles, assim como seu corpo teórico. Paul Rabinow (1999), em Representações são fatos sociais, opera a idéia de pensamento como um conjunto de práticas que são públicas e historicamente localizáveis. Ainda que produto de um conjunto teórico elaborado, consultas médicas, internações e cultos de exorcismo são sobretudo práticas. Produtos passíveis de um consumo que não é universal, mas destinados a uma população com características que estão implicadas na funcionalidade do processo.

Citando Foucault, Rabinow (1999) pensa a verdade como um sistema de procedimentos ordenados para regulamentação, distribuição e operação de afirmações e conectada, numa relação circular, com sistemas de poder que a produzem e a confirmam e com efeitos de poder que ela induz e que a estendem (p. 79). É possível identificar a narrativa de Aparecida como uma forma de operacionalizar experiências com uma finalidade de resolução de um conflito pessoal. Esta operação ocorre ainda num sistema que implica assimetria na relação entre os promotores das práticas e Aparecida. Esta relação de poder confirma a veracidade da narrativa.

\section{Referências}

AlEXANDer, P. J.; Joseph, S.; DAs, A. Limited utility of ICD-10 and DSM-IV classification of dissociative and conversion disorders in India. Acta Psychiatrica Scandinavian, v. 95, n. 3, p. 177-82, mar./1997. 


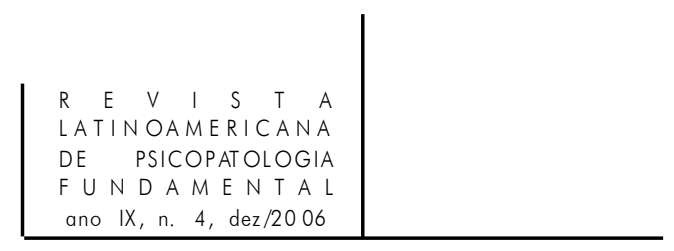

Akyux, G.; Dogan, O.; Sar, V.; Yargic, L. I.; Tuchun, H. Frequency of dissociative identity disorder in the general population in Turkey. Comprehensive Psychiatry, v. 40, n. 2, p. 151-9, mar.-apr./1999.

Beng-Yeong, Ng. Phenomenology of trance states seen at a psychiatric hospital in Singapure: a cross-cultural perspective. Transcultural Psychiatry, v. 37, n. 4, p. 561-580. Dec./2000.

Benjamin, W. Obras Escolhidas. O narrador - v. 1. 3. ed. São Paulo: Brasiliense, 1987.

Bourguignon, E. Multiple personality, possession trance and the psychic unit of mankind. Ethos, v. 17, n. 3, p. 371-84, 1989.

The DSM-IV and cultural diversity. Transcultural Psychiatry Research Review, v. 29, n. 4, p. 330-2, 1992.

Csordas, T. Health and the holy in African and Afro-American spirit possession. Social Science and Medicine, v. 24, n. 1, p. 1-11, 1987.

DAs, P. S.; S AXENA, S. Classification of dissociative states in DSM-III-R and ICD-10 (1989 draft). A study of Indian out-patients. British Journal of Psychiatry, n. 159, p. 425-7, sep./1991.

Dorahy, M. J.; S chumaker, J. F.; Krisnamurthy, R.; Kumar, P. Religious ritual and dissociation in India and Australia. Journal of Psychology, v. 131, n. 5, p. 471-6, sep./1997.

Douglas, M. Thought Style Exemplified. The Idea of the Self, in Risk and Blame Essays in Cultural Theory. London: Routledge, 1992. p. 211-34.

Escobar, J. L. Transcultural aspects of dissociative and somatoform disorders. Psychiatric Clinical North America, v. 18, n. 3, p. 555-69, sep./1995.

Friedl, M. C; Draijer, N.; de Jorge, P. Prevalence of dissociative disorders in psychiatric in-patients: the impact of study characteristics. Acta Psychiatrica Scandinavian, v. 102, n. 6, p. 423-8, dec./2000.

Gast, U.; Rodewald, F.; Nickel, V.; EnRich, H. M. Prevalence of dissociative disorders among psychiatric inpatients in a German university clinic. Journal of Nervous and Mental Disease, v. 189. n. 4, p. 249-57, apr./2001.

Gleaves, May e Cardeña. An examination of the diagnostic validity of dissociative identity disorder. Clinical Psychology Review, v. 21, n. 4, p. 577-608, Jun./2001

Halperin, D. Trance and Possession: are they the Same. Transcultural Psychiatric Research Review, v. 33, n. 1, p. 33-42, 1996.

Haugen, M.C.; Castillo, R. J. Unrecognized dissociation in psychotic outpatients and implications of ethnicity. Journal of Nervous Mental Disease, v. 187, n. 12, p. 751-4, dec./1999. 


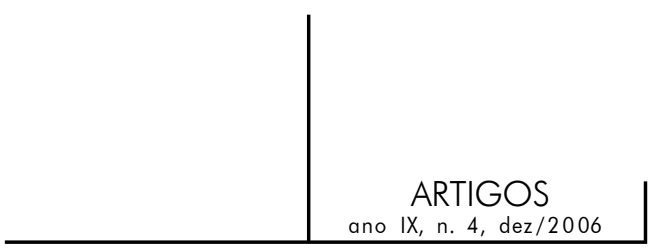

Hess, D. Ghosts and domestic politics in Brazil: some parallels between spirit possession and spirit infestation. Ethos, v. 18, n. 4, p. 407-38.

Hockman, J.; Pope, H. G. Jr. Debating dissociative diagnoses. American Journal of Psychiatry, v. 154, n. 6, p. 887-8, jun./1997.

Hollan, Douglas. The relevance of person-centered ethnography to cross-cultural psychiatry. Transcultural Psychiatry, v. 34, p. 219-234, Jun./1997.

KIRmayer, L. J. Taking possession of trance. Transcultural Psychiatric Research Review, n. 39, p. 283-6, 1992.

Pacing the Void: Social and Cultural Dimensions of Dissociation. In: SPIEGEL, D. (ed.). Dissociation: Culture, Mind and Body (91-122). Washington, DC: American Psychiatry Press, 1994.

Kirmayer, L.J. \& Santhanan, R. The anthropology of hysteria conversion disorder. In: Halligan, P.W., Bass, C. \& Marshall, J. C. (eds.). Contemporary Approaches to the Study of Hysteria: Clinical and Theoretical Perspectives. Oxford: Oxford University Press, 2001. p. 251-70.

Kleinman, A. Patients and Healers in the Context of Culture. University of California Press, 1980.

Rethinking Psychiatry: From Cultural Category to Personal Experience. New York: The Free Press, 1988.

Kluft, R. P.; Foote, B. Dissociative identity disorder: recent developments. American Journal of Psychotherapy, v. 53, n. 3, p. 283-8, summer-1999.

Lewis, I. M. Êxtase religioso. São Paulo: Perspectiva, 1977.

Neliah, J.C. A psychodynamic view of psychosomatic medicine. Psychosomatic Medicine, v. 62. n. 3, p. 299-303, May-Jun./2000.

North, C. S. The toll of refugee status and the state of trauma research. Archives of General Psychiatry, v. 58, n. 5, p. 483-4, may/2001.

Pope Jr., H.G., Oliva, O.S., Hudson, J.I., Bodkin. J.A., Gruber. A.J. Attitudes toward DSM-IV dissociative disorders diagnoses among board - Certified American psychiatrists. American Journal Psychiatry, v. 156. n. 2, p. 321-3, Feb./1999.

Rabnow, Paul Antropologia da razão: ensaios de Paul Rabinow. Organização e tradução de João Guilherme Biehl. Rio de Janeiro: Relume-Dumará, 1999.

RedKo, C.P. Fighting against the "evil” Religious and cultural construction of the first psychotic experience of young people living in São Paulo, Brazil (2000).A thesis submitted to the Faculty of Graduate Studies and Research in partial fullfilment of the requirements of the degree of Ph.D in Anthropology McGill University. 


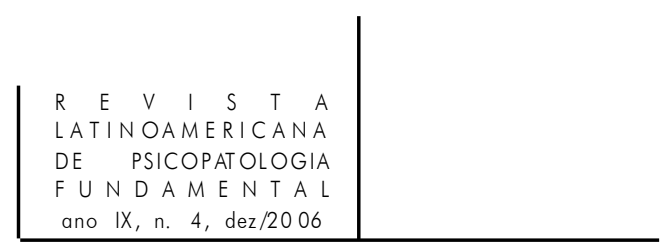

Ricoeur, Paul (1994). A história e a narrativa. In: Tempo e narrativa. Campinas: Papirus, 1994. t. 1.

Sar, V.; Tutkun, H.; Alyanak, B.; Bakim, B.; Baral, I. Frequency of dissociative disorders among psychiatric outpatients in Turkey. Compreensive Psychiatry, v. 41, n. 3, p. 216-22, may/2000.

Sсотт, J. W. (1999). Experiência em falas de gênero. In: da S. Leite, Alcione; Lago, Mara Coelho de Souza e RAmos, Tânia Regina Oliveira (orgs.). Teorias, análises, leituras. Florianópolis: Mulheres.

Somer, Eli and SAadon, Meir Stambali. Dissociative possession and trance in a Tunisian healing dance. Transcultural Psychiatry, n. 37, p. 580-600, Dec./2000.

Thompson, E. P. Formação da classe trabalhadora inglesa. S.I/E/ed., 1990.

TutKum, H.; Sar, V.; Yargic, L. I.; Ozpulat, T.; Yanik, M.; Kiziltan, E. Frequency of dissociative disorders among psychiatric inpatients in a Turkish University Clinic. Am J. Psychiatry, v. 155, n. 6, p. 800-5, jun./1998.

Zatzick, D. F; Marmar, C. R.; Weiss, D. S; MetZleR, T. Does trauma-linked dissociation vary across ethnic groups? Journal of Nervous and Mental Disease, v. 182, n. 10, p. 576-82, oct./1994.

\section{Resumos}

Disociación de la conciencia es un fenómeno que ocurre en contextos culturales, como rituales religiosos, así como en situaciones médicas. Las clasificaciones diagnósticas buscan distinguir esas dos clases de fenómenos. Aunque la diferenciación sea hecha, las personas que presentan experiencias disociativas buscan diferentes posibilidades interpretativas para esos fenómenos. El presente artículo procura a través de una etnografía centrada en la persona describir esos diferentes significados encontrados por una paciente con experiencias disociativas. Además identificamos en la narrativa de esas experiencias la especificidad del fenómeno psicopatológico de la disociación.

Palabras clave: Disociación, etnmografia centrada na pessoa, narrativa, psiquiatria cultural

La dissociation de la conscience est un phénomène qui se présente dans des situations culturellement sanctionnées, comme des rituels religieux, aussi bien que dans des contextes médicaux. Les classifications du diagnostique cherchent à différencier ces épisodes en deux phénomènes distincts. Néanmoins, les individus présentant un état 


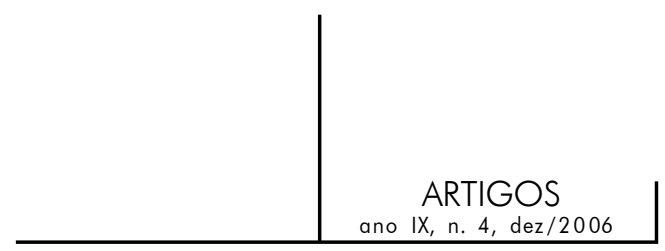

dissociatif cherchent, en général, différentes interprétations pour ce phénomène. Cette étude a pour but de décrire les itinéraires de différents savoirs parcourus par ces patients tout en s'appuyant sur une ethnographie centrée sur la personne. On reconnaîtra encore dans la narrative de l'expérience dissociative quelques spécificités liées au phénomène psychopathologique de la dissociation.

Mots clés: Dissociation, ethnographie centrée sur la personne, narrative, psychiatrie culturelle

The dissociation of consciousness is a phenomenon that can be seen in both culturally sanctioned situations (such as in religious cults) and in medical settings. Diagnosis classification manuals, such as the DSM-IV and the ICD-10, seek to separate these situations into cultural phenomena and mental disorders, respectively. Despite this difference in diagnoses, patients who have had dissociative experiences often seek different meanings for the phenomena. Through an ethnography centered on the person, this article presents a description of different experiences of a female patient who has had dissociative experiences. The psychopathologic specificities of the construction of the narrative based on these experiences are also discussed.

Key words: Dissociation, etnography centered on the person, narrative, cultural psychiatry 